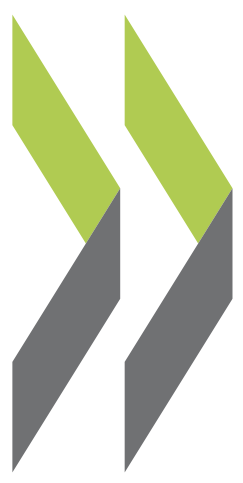

PEB Exchange, Programme on Educational Building 2008/03

\title{
Changing School Architecture in Zurich
}

\author{
Mark Ziegler, \\ Daniel Kurz
}

https://dx.doi.org/10.1787/245422646704 


\section{Changing School Architecture in Zurich}

\section{By Mark Ziegler and Daniel Kurz, City of Zurich Real Estate Management, Switzerland}

Changes in the way education is delivered has contributed to the evolution of school architecture in Zurich, Switzerland. The City of Zurich has revised its guidelines for designing school buildings, both new and old. Adapting older buildings to today's needs presents a particular challenge. The authors explain what makes up a good school building and provide a set of design recommendations.

Over the last 20 years, the City of Zurich has experienced a boom in school building construction. The demand for new buildings and the refurbishment of old ones was prompted by growing neighbourhoods and by education's changing requirements. Since 1998, Zurich has built 4 large schools and has renovated or extended 15 others.
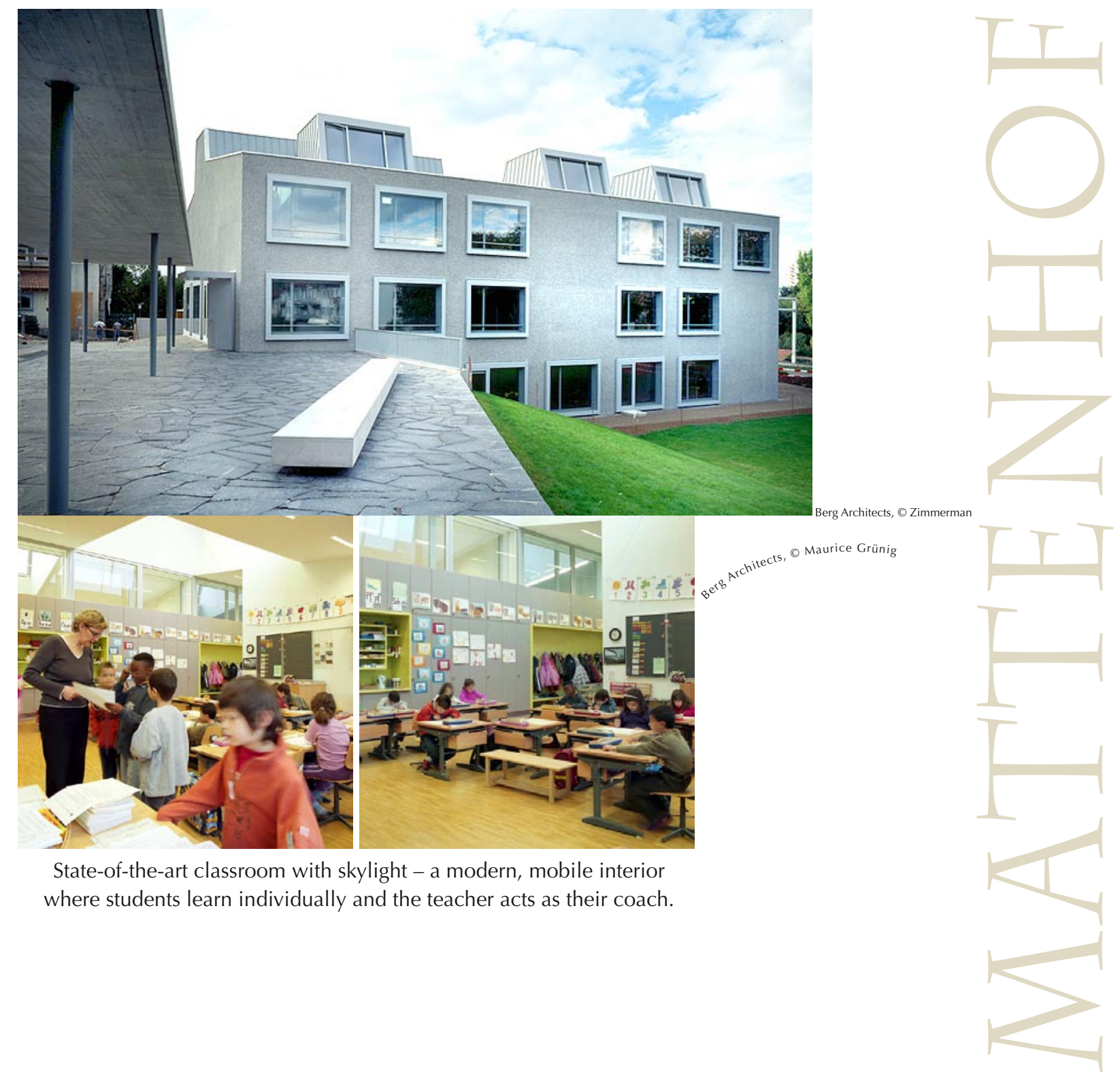

State-of-the-art classroom with skylight - a modern, mobile interior where students learn individually and the teacher acts as their coach. 


\section{THE NEED FOR CHANGE}

In the mid 1990s, calls for reform began to shake the public school system - the Volksschule - in a manner unprecedented in its 175 year existence. Modern teaching was becoming more individualised, allowing each child to learn at his or her own pace, while group learning and activities involving more than one class were increasing. The teacher was no longer the sole master in his or her classroom, but was expected to work in a team. As innovative educators began practicing integrative, individual and multi-facetted forms of teaching, they found that the walls within which they worked were becoming a hindrance. In addition, the demand for day-care facilities experienced a dramatic increase.

Faced with both a building boom and new needs for school users, the City of Zurich modernised its guidelines for school construction. The new guidelines lay out a planning process which involves school authorities, school administrators, building authorities and, since 2002, the newly founded Public Real Estate Agency. For each building project, open design competitions are organised.

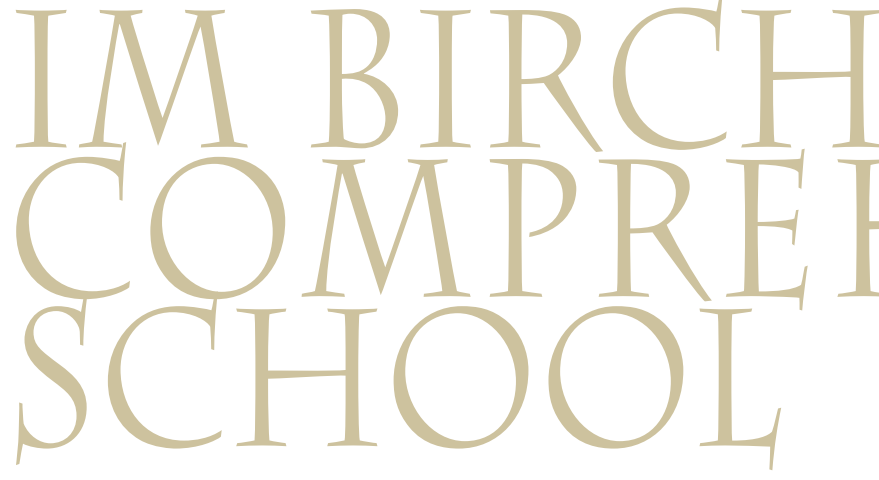

One of the first projects to be commissioned under the new guidelines was Im Birch Comprehensive School in Oerlikon. Of the three teams qualified for the second round in the architectural competition, only one actually thought out the project from an educator's view, adapted their design accordingly and offered an elegant solution. To allow for a more flexible use of space, architect Peter Märkli proposed classroom clusters with a common foyer shared by a number classes for group activities and interclass co-operation.

The inauguration of Im Birch school in 2004 was marked by an international symposium on and an exhibition presenting 31 cutting-edge school buildings from Switzerland, as well as from Denmark, Finland, Germany and the Netherlands. ${ }^{1}$ The symposium demonstrated that many countries face similar architectural challenges and that more flexible room arrangements and open-space designs are replacing the traditional corridor-type school building designs.

1. See Kurz, D. and A. Wakefield (eds.) (2004), School Buildings: The State of Affairs. The Swiss Contribution in an International Context, City of Zurich Building Department, School and Sports Department, Swiss Federal Institute of Technology, Zurich University of Applied Science, School of Education, Basel (224 pages, essays, plans and photographs of 31 European school-buildings and projects).
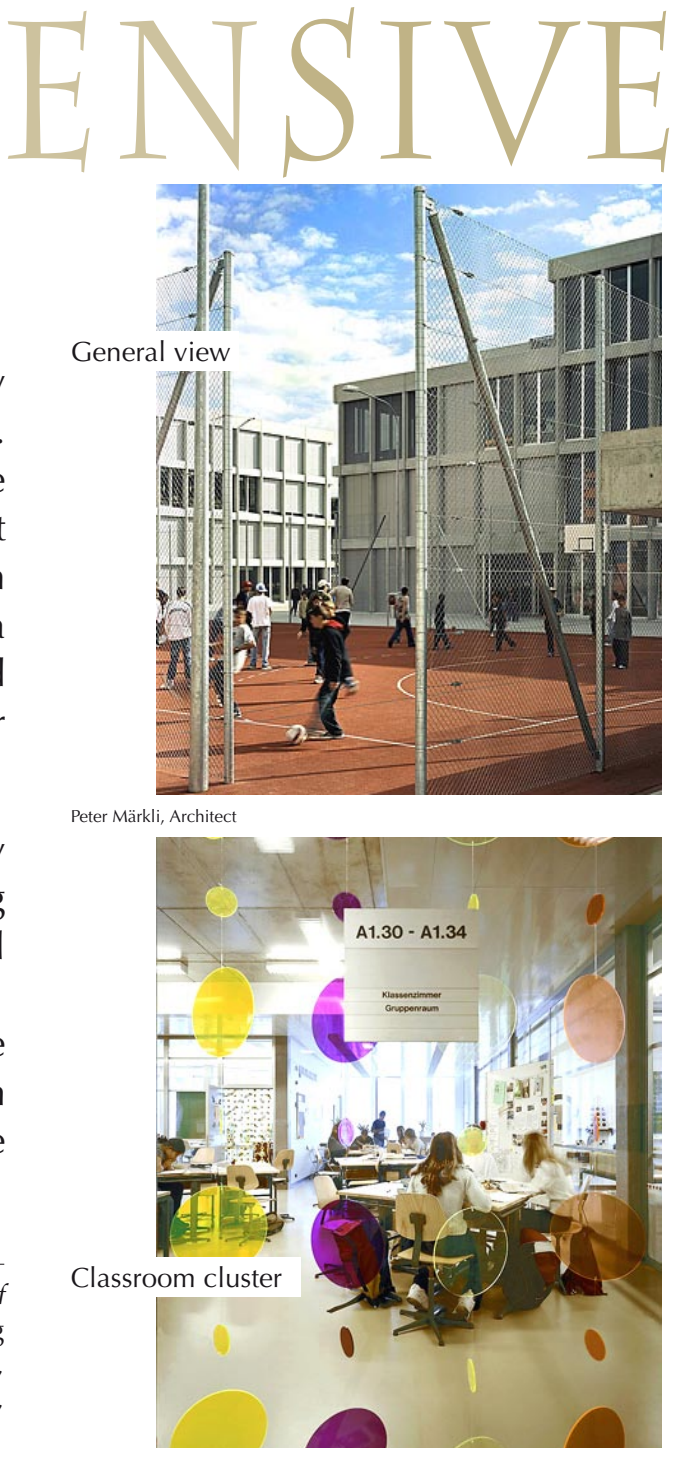


\section{THE CHALLENGE}

Until the mid 1950s, a Zurich school consisted basically of a hallway with a string of rooms latched onto it. Inside each room, one teacher would teach one class. Occasionally, the class would go to the gymnasium, to the auditorium, to the cooking-classroom or to a workshop. After the 1950s, more and more specialised rooms such as the library and laboratories were added. As teaching methods changed, group learning areas were required. Then day-care rooms were needed. And finally offices for the school administrators, workspace for part-time or specialist teachers, and rooms for music and therapy (speech therapy and other remedial training) were included. However, school corridors in Zurich were frequently used as learning space with flagrant disregard for fire regulations, while group learning rooms were neglected.

The problem had changed. Group learning areas as separate rooms require a second teacher to keep order. This negates the integrative effect of team-teaching. If the group learning area is adjacent to a classroom, it soon turns into an extension of the classroom and is thus no longer accessible to other teachers, counteracting any attempt at interclass co-operation.

Zurich's 1999 cantonal guidelines for primary and lower secondary schools allow one group learning area per two classes. At upper secondary level there is one group learning area per class. This causes problems in that on the one hand the flexibility of use is limited and on the other the spatial solution does not solve the operational problem.

The City of Zurich has reacted by defining a new concept. Instead of separate group learning rooms, the new norm is bigger classrooms with integrated group learning space and a small number of separate rooms. The latter are assigned to music, therapy and other specialist teachers and are thus well booked.

\section{A GOOD SCHOOL BUILDING}

What makes a good school building? The most important aspects are the flexibility and adaptability of spaces. School buildings must be able to change with the evolving demands placed on them by their users. Buildings from the late 19th century, designed for classes of 60 to 70 children, often have huge classrooms measuring 90 to $100 \mathrm{~m}^{2}$. Wide corridors were built to permit the flow of students.

Reforms of the 1930s and 1950s demanded smaller, more intimate classrooms, reducing class sizes to 20 to 30 students. Functionalist architects promoted pavilion schools, where each class had its own cozy $69 \mathrm{~m}^{2}$ of space. Corridors and stairwells were reduced to the minimum, making these buildings extremely compact. Today, however, these tailor-made solutions have proven to be a burden. Modern teaching methods require more and more flexible spaces: computer workspaces, spaces for group learning, day-care centres and administrative offices.

The old school buildings with their oversized rooms have proven more adaptable to modern requirements than modern functionalist pavilion types, as they often permit repartitioning of their spaces.

From a real estate point of view, the value of a building is defined by its usability. Of course, a school building also has financial, architectural and cultural value. But if it can no longer fulfil its function, it must be either adapted or put to a different use. In the worst instance, it must be replaced. 


\section{Zurich's traditional school layouts}
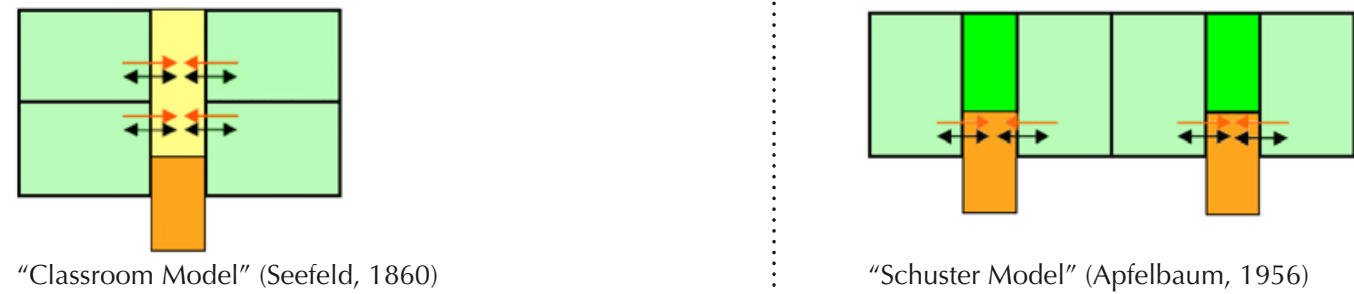

"Schuster Model" (Apfelbaum, 1956)
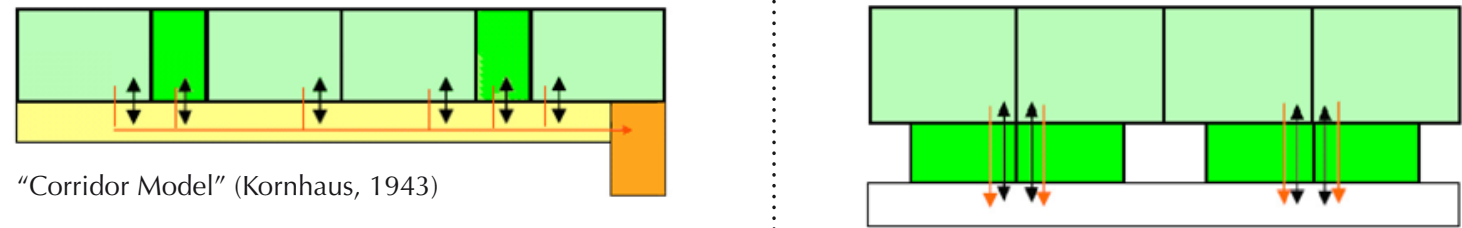

"Pavillion Model" (Chriesiweg, 1956)

Classrooms

Therapy/Group

Corridor

Stairwell

Since educational concepts are subject to change, a sustainable school building must not only be functional and robust, but also adaptable to changing requirements. In order to be adaptable, those responsible for school architecture need to respect the following demands:

1. Design classrooms as polyvalent spaces which include an integral group working area.

2. Keep the load-bearing structure separate from the finishes to enable rearranging walls.

3. Design utilities and technical installation with easy access and enough space to permit later additions in elevator shafts.

4. Design access in such a way that the gymnasium, auditorium, day-care and library can be used outside school hours without entering the classroom areas.

5. Minimise specialised fittings and infrastructure. Define the use of the space by furniture alone as much as possible.

6. Make access spaces (corridors) usable for the school. By separating daily access spaces from fire escapes, these areas can serve for interclass co-operation, exhibitions, presentations and group learning.

7. Concentrate and minimise specialised spaces (e.g. laboratories, school kitchens).

These recommendations have been applied both in Zurich at the Leutschenbach School (by Christian Keretz) and in Minneapolis (United States) at the Interdistrict Downtown School (by the Cuningham Group). The different fire-codes effect the design, but the principle remains the same: classrooms are ancillary to a common space so that exchange can take place. The US school has an even more radical open-space design than the Zurich one, doing away with walls between the classroom and the common space, and encouraging highly innovative and team-oriented teaching methods. 

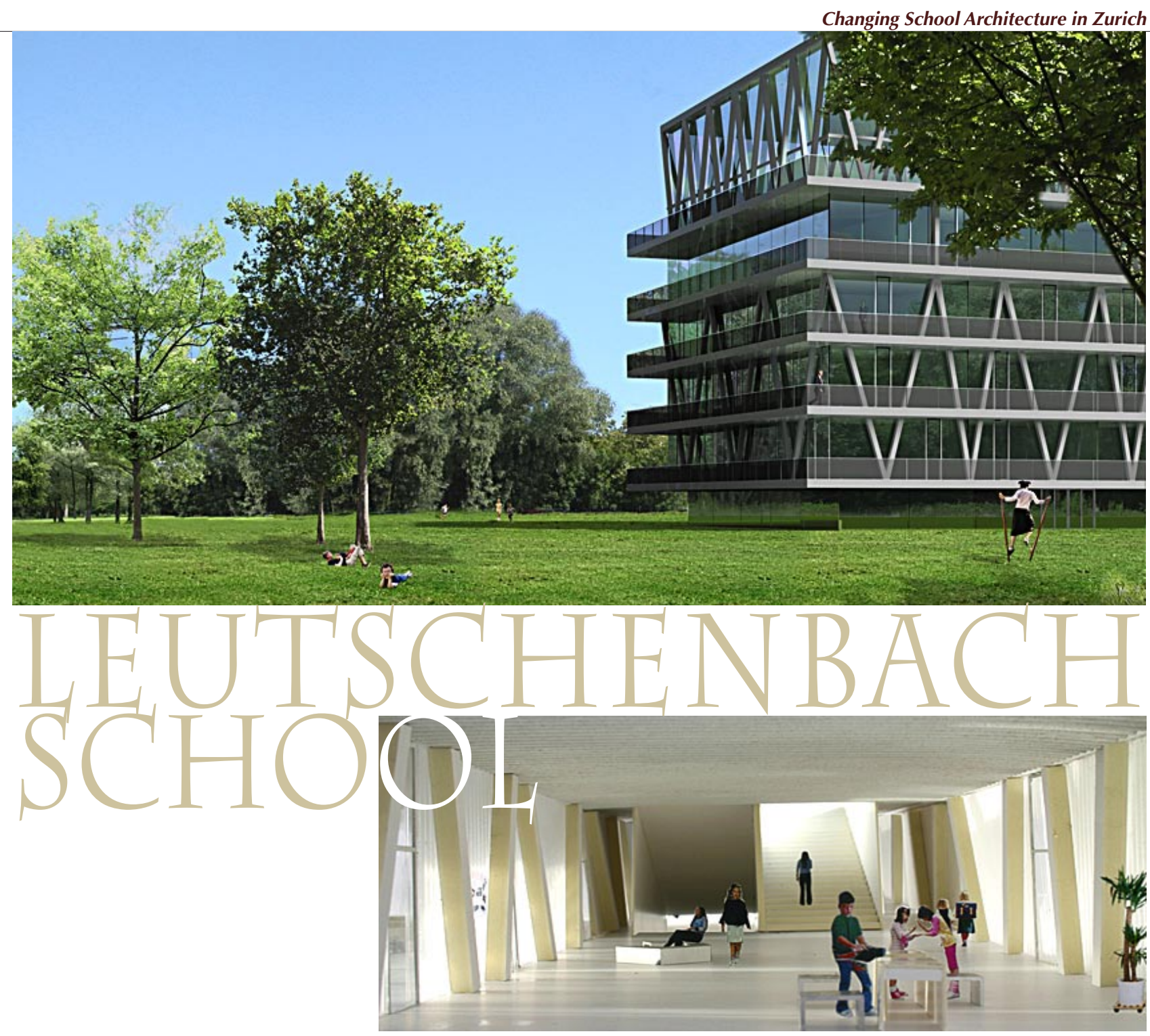

\section{Modern layouts}

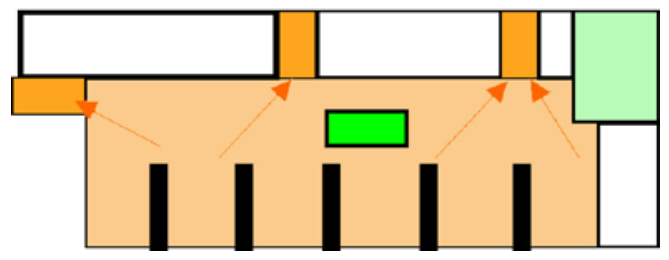

Interdistrict Downtown School, Minneapolis

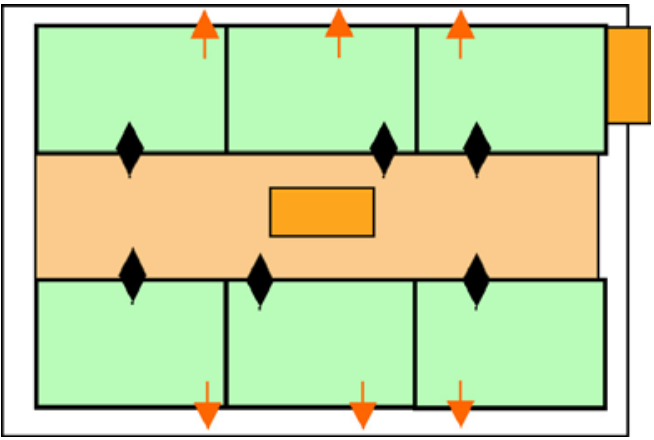

Leutschenbach School, Zurich

Classrooms

Therapy/Group

Corridor

Stairwell

Common space 


\section{CONCLUSIONS}

School buildings are important not only as workspaces for teachers and children, but also as public buildings which mirror a period of time and thought. This is the case in Zurich, where the public school is an integral part of society and draws its strength from that fact. The Volksschule demonstrates innovative architecture reflecting its history, its adaptability and, above all, belief in its future.

For more information, visit www.stadt-zuerich.ch/hochbau or contact:

Mark Ziegler

Stadt Zürich

Immobilien-Bewirtschaftung

Lindenhofstrasse 21

Postfach, 8021

Zurich, Switzerland

E-mail:markus.ziegler@zuerich.ch

Daniel Kurz

Stadt Zürich

Amt für Hochbauten

Lindenhofstrasse 21

Postfach, 8021

Zurich, Switzerland

E-mail:daniel.kurz@zuerich.ch 


\section{ORGANISATION FOR ECONOMIC CO-OPERATION AND DEVELOPMENT}

The OECD is a unique forum where the governments of 30 democracies work together to address the economic, social and environmental challenges of globalisation. The OECD is also at the forefront of efforts to understand and to help governments respond to new developments and concerns, such as corporate governance, the information economy and the challenges of an ageing population. The Organisation provides a setting where governments can compare policy experiences, seek answers to common problems, identify good practice and work to co-ordinate domestic and international policies.

The OECD member countries are: Australia, Austria, Belgium, Canada, the Czech Republic, Denmark, Finland, France, Germany, Greece, Hungary, Iceland, Ireland, Italy, Japan, Korea, Luxembourg, Mexico, the Netherlands, New Zealand, Norway, Poland, Portugal, the Slovak Republic, Spain, Sweden, Switzerland, Turkey, the United Kingdom and the United States. The Commission of the European Communities takes part in the work of the OECD.

OECD Publishing disseminates widely the results of the Organisation's statistics gathering and research on economic, social and environmental issues, as well as the conventions, guidelines and standards agreed by its members.

This work is published on the responsibility of the Secretary-General of the OECD. The opinions expressed and arguments employed herein do not necessarily reflect the official views of the Organisation or of the governments of its member countries.

No reproduction, copy, transmission or translation of this publication may be made without written permission. Applications should be sent to OECD Publishing rights@oecd.org or by fax 331452499 30. Permission to photocopy a portion of this work should be addressed to the Centre français d'exploitation du droit de copie (CFC), 20, rue des Grands-Augustins, 75006 Paris, France, fax 331463467 19, contact@cfcopies.com or (for US only) to Copyright Clearance Center (CCC), 222 Rosewood Drive, Danvers, MA 01923, USA, fax 1978646 8600, info@copyright.com. 